\title{
Rodrigues, M. L. \& Heitor, M. (Eds.) (2015). 40 ANOS DE POLÍTICAS DE CIÊNCIA E DE ENSINO SUPERIOR. CoImbra: Almedina.
}

\author{
Madalena Oliveira
}

Ainda que a primeira universidade portuguesa, a Universidade de Coimbra, tenha sido fundada no século XIII, a história das políticas científicas e do ensino superior em Portugal conta-se em páginas relativamente breves até à Revolução dos Cravos de 1974'. É, com efeito, nas últimas quatro décadas, coincidentes com a experiência democrática, que se situa a cronologia mais intensa do desenvolvimento da ciência e da educação universitária do país. Desdobrado em capítulos focados na necessidade de organização interna e de expansão internacional, este percurso recente de Portugal constitui o objeto central de 40 anos de políticas de ciência e de ensino superior, um volume de quase 1200 páginas organizado por Maria de Lurdes Rodrigues e Manuel Heitor (Rodrigues \& Heitor, 2015), com o contributo de 41 autores e 23 políticos e cientistas portugueses. Proporcional à densidade das transformações operadas no setor no pós 25 de Abril, a extensão deste livro reflete a complexidade do campo científico, sobretudo no que diz respeito à gestão de recursos, à definição de prioridades e estratégias de crescimento, a modelos de regulação e avaliação e à necessária interação com a sociedade.

Descrita como "uma obra antológica" (p. 19), esta publicação fixa-se, segundo os editores, no propósito de constituir "uma base para informar a formulação e a implementação de novas políticas de ciência e ensino superior" (p. 22). Apesar desta orientação para o futuro, é a leitura do passado recente proposta pelos 58 textos que o integram que faz deste livro coletivo, dedicado à memória de José Mariano Gago, uma obra necessária e inescapável para a compreensão do espaço de produção de conhecimento e saber em Portugal. Editado 25 anos depois da publicação de Manifesto para a Ciência em Portugal (Gago, 2008 [1990]), o trabalho coordenado por Maria de Lurdes Rodrigues e Manuel Heitor não é indiferente à herança do tutelar da pasta da Ciência entre 1995 e 2002 e da Ciência e do Ensino Superior entre 2005 e 2011, cuja referência é inevitável em vários capítulos e nos testemunhos finais em que se constata que o nome e a ação de Mariano Gago "estão indelevelmente associados à evolução da ciência em Portugal" (p. 23).

$\mathrm{Na}$ abertura de 40 anos de políticas de ciência e de ensino superior, o leitor é convidado a uma dupla análise. Por um lado, uma análise cronológica das políticas públicas, assinada por Maria de Lurdes Rodrigues, que recua à Primeira República para aí iniciar

\footnotetext{
1 Num breve livro sobre a Ciência em Portugal, Carlos Fiolhais explica que "o século XX português foi, a nível educativo, nas suas primeiras três quartas partes, o prosseguimento do século XIX", o que se traduziu, segundo o autor, pela manutenção de uma "reduzida escolarização da população, designadamente no ensino superior, e, portanto, a impossibilidade de uma aposta substancial na ciência" (Fiolhais, 2011, p. 25).
} 
um exame dos antecedentes da construção do sistema científico e do desenvolvimento do ensino superior nacional, que se desenrola, segundo a autora, em cinco fases específicas a partir dos últimos anos do Estado Novo. Por outro, uma análise dos impactos, proposta por Susana da Cruz Martins e Cristina Palma Conceição, para quem "uma evolução positiva dos vetores em análise" no campo da ciência e do ensino não evita "desafios e dilemas de difícil tratamento" (p. 76). Não obstante a "interdependência e simbiose no desenvolvimento do ensino superior e da ciência" (p. 51) reconhecidas pelas autoras, depois dos capítulos introdutórios, duas grandes partes (só aparentemente separáveis) organizam o corpo do livro. A primeira centra-se na construção e desenvolvimento do sistema científico e reúne um conjunto de participações sobre política científica, sobre instituições, recursos financeiros e infraestruturas e sobre as ligações da ciência à sociedade. A segunda examina a expansão e diversificação do ensino superior expressa na organização e desenvolvimento institucional, na massificação do acesso, na problemática da autonomia e modelos de gestão das universidades e nos instrumentos de financiamento, regulação e avaliação.

Do ponto de vista histórico, qualquer que seja o indicador analisado, é comum o entendimento de que até 1974 o país sofreu um atraso brutal relativamente aos níveis que já se registavam noutros países, tendo sido muito pouco expressiva a atuação dos organismos até então dedicados às atividades de investigação (nomeadamente a Junta Nacional de Educação, criada em 1929 e transformada em Instituto para a Alta Cultura, a partir de 1936). É a criação, em 1967, da Junta Nacional de Investigação Científica e Tecnológica (JNICT), que "marca o início do planeamento científico em Portugal", como lembra Manuel Heitor (p. 92). Para Maria Fernanda Rollo, este organismo "representava, por altura da Revolução, a manifestação mais arrojada das ambições que procuravam informar uma política científica e tecnológica nacional" (p. 147). É ainda na vigência desta instituição que Portugal começa a usufruir de fundos europeus, "redesenhando-se a JNICT", como explica Tiago Brandão, "na transição para os anos 1990, como uma autêntica agência de financiamento beneficiando da diversificação das fontes de financiamento do 'sistema de C\&T' enquanto resultado direto da adesão à Comunidade Europeia" (p. 215).

A integração no espaço político e económico europeu é, depois do 25 de Abril, o principal fator de desenvolvimento do campo académico-científico português, que representou a orientação das ações para parâmetros como a internacionalização das unidades de investigação e dos próprios investigadores. Maria Teresa Patrício e Tiago Santos Pereira referem a este propósito "a importância da mobilidade e da formação avançada no estrangeiro", bem como "uma nova capacidade de atração de estudantes de doutoramento e investigadores estrangeiros para Portugal" (p. 287) e a "participação portuguesa em organismos e instituições internacionais da ciência" (p. 288), aspetos que se refletem "nos elevados padrões de publicação científica em coautoria internacional da comunidade científica portuguesa" (p. 287).

A variável mais sensível das matérias de política científica é a do financiamento e do modo como os fundos disponíveis se distribuem pelas unidades de investigação. Os 
Laboratórios Associados são, neste contexto, uma espécie de estrutura premium da ciência em Portugal absorvendo uma fatia muito significativa do financiamento disponível para as instituições de investigação, com "dotação financeira para a contratação de investigadores" (p. 327), o que é praticamente inviável para qualquer outro tipo de unidade, cujos recursos humanos se restringem à contratação de bolseiros de investigação e de gestão de ciência e tecnologia. Não obstante a desigualdade da distribuição de recursos quer entre instituições quer entre áreas científicas, há uma ideia consensualizada entre os autores desta obra de que, depois da integração na União Europeia e até à crise económica que começou em 2009, houve um investimento crescente em ciência, que se traduziu num aumento expressivo do número de doutorados, de emprego científico, de publicações e de projetos tanto de investigação como de gestão técnica e de cálculo científico.

Para além da matemática dos recursos financeiros e dos indicadores de produtividade, as instituições de ciência confrontam-se hoje também com o desafio de serem diretamente relevantes para a sociedade. Exige-se-lhes a "promoção de cultura científica" que implica, como explica Cristina Palma Conceição, a "melhoria dos níveis de literacia científica das populações" e o "reforço da incorporação dos conhecimentos e orientações da ciência nas práticas e disposições dos indivíduos" (p. 465). Deste requisito emerge a comunicação da ciência como imperativo de toda a ação de investigação, mas que, "em Portugal, continua precária", sendo vista por muitos, dizem Catarina Amorim e Júlio Borlido Santos, "como pouco mais do que um instrumento de relações públicas da instituição" (p. 468). Para os autores, "o conjunto de comunicadores de ciência é desorganizado, crescendo aleatoriamente e, em grande parte, sem uma visão nacional que os suporte" (p. 468), uma ideia partilhada por Marta Entradas, para quem "a comunicação pública de ciência é ainda uma atividade pontual para muitas unidades de investigação" (p. 515), devido à falta de recursos humanos e financeiros, de profissionalização e de envolvimento dos investigadores em ações de comunicação pública.

A história do ensino superior nas quatro décadas que se seguiram à Revolução de 74 não é muito diferente do enquadramento do campo científico em termos gerais. Também do ponto de vista da educação se assistiu a um aumento tanto do número de instituições e de oferta formativa como de alunos, embora Portugal continue, sublinham Alberto Amaral e Orlanda Tavares, "a apresentar uma população com baixas qualificações, quando comparado com a média europeia" (p. 558). Para além da democratização do acesso ou expansão do número de inscritos, que Augusto Santos Silva e Ana Serrano dizem não ser "uma singularidade portuguesa" (p. 648), as políticas neste setor visaram também dois outros imperativos: a modernização e a especialização do ensino superior, por um lado, e a internacionalização e a mobilidade, por outro.

Do ponto de vista político, o chamado Processo de Bolonha, iniciado em 1999 e implementado a partir de 2006, foi talvez o vetor mais impactante da reforma do ensino superior no período dos 40 anos de democracia. Apresentado como um "instrumento para a consecução da Área Europeia de Ensino Superior", o Processo de Bolonha é analisado como um sonho mais ou menos falhado. Amélia Veiga explica que a fragilização do propósito de "criar um sólido edifício para o ensino superior europeu" se deve "à forma 
como Bolonha se centrou nos meios (instrumentos e procedimentos), em prejuízo dos fins de maior coesão social, através da mobilidade e empregabilidade proporcionadas pelo ensino superior" (p. 606).

Demonstrando que a mobilidade de estudantes no espaço europeu de ensino aumentou exponencialmente, Susana da Cruz Martins e Alexandra Duarte constatam que "as condições socioeconómicas [dos] estudantes parecem pesar de forma flagrante nos planos de mobilidade e na sua concretização efetiva" (p. 642). Já no que diz respeito aos movimentos de incoming, o acolhimento de estudantes estrangeiros parece ter "um efeito pressionante sobre a qualidade do sistema português e (...) de abertura e modernização das suas organizações de educação terciária" (p. 643).

Se os discursos sobre o crescimento são mais ou menos unânimes, porque decorrem do caráter demonstrativo dos números, relativamente aos modelos de gestão, o consenso fixa-se em torno do princípio de autogoverno e autonomia. Num texto em que avalia a evolução dos sistemas de governo das universidades portuguesas, Vital Moreira considera que "o autogoverno universitário não é incompatível com a eficácia e eficiência da gestão administrativa" (p. 812). Júlio Pedrosa, por seu turno, adverte que "a autonomia entendida como direito ao autogoverno não pode ser confundida com a liberdade académica, isto é, com a liberdade de investigar, de criar conhecimento, de ensinar e de aprender" (p. 822). No entanto, como assinala António M. Magalhães, "a atribuição de autonomia gera tensões na relação entre a condução política do sistema protagonizada pelo Estado e as atividades de governação exercidas pelas instituições de ensino superior" (p. 827).

Em matéria de financiamento, o ensino superior tem sido especialmente desafiado pelas lógicas de mercado. Pedro Nuno Teixeira confirma que "a crescente relevância dos mecanismos de mercado tem tido uma influência crescente no tipo de políticas adotadas neste setor" (p. 859). Esta é talvez a única aproximação que o autor faz a uma ideia defendida por Moisés de Lemos Martins num texto publicado na revista Comunicação $Q$ Sociedade sobre "a liberdade académica e os seus inimigos", onde defende que

aquilo que faz a natureza da universidade, hoje, é a ideologia comercial: as universidades são empresas; a educação são serviços; o ensino e a investigação são oportunidades de negócios; os professores são profissionais de serviços ou consultores; os alunos são clientes. (Martins, 2015, p. 409)

$\mathrm{Na}$ extensão das questões de financiamento, a avaliação da qualidade do ensino superior, que hoje está a cargo da Agência de Avaliação e Acreditação do Ensino Superior ( $\left.A_{3} E S\right)$, é a mais recente obsessão das universidades, dado que, como assinalam Cláudia S. Sarrico e Maria J. Rosa, "o que é relevante no mercado de trabalho para diplomados é menos a posse de um diploma, e mais a qualidade percebida desse diploma" (p. 881). A relação entre o emprego e a qualidade é, por sinal, indisfarçável, já que, lembra Mariana Gaio Alves, "a informação sobre emprego faz parte dos critérios de avaliação da qualidade", sendo os empregadores "envolvidos nos processos de avaliação de qualidade" (p. 889). 
Ainda que aponte algumas dificuldades e desafios, 40 anos de políticas de ciência e de ensino superior é um livro de tom positivo, mais centrado na afirmação de que "o atraso crónico de Portugal em ciência e tecnologia foi vencido após 40 anos de democracia e 30 anos de integração europeia" (p. 1069) do que no debate dos valores que hoje definem as instituições de ensino e investigação. Não obstante a espessura física da obra, o milhar de páginas que a compõe não cobre suficientemente a pergunta que Zara Pinto Coelho e Anabela Carvalho fazem na introdução ao livro Academics responding to discourses of crisis in higher education and research: "como lidamos com estes desafios que são ao mesmo tempo obstrutivos e destrutivos e criamos oportunidades?" (Coelho \& Carvalho, 2013, p. 5). Ao invés deste questionamento, o epílogo, assinado por Manuel Heitor, que no início de 2016 assumiu as funções de Ministro da Ciência, Tecnologia e Ensino Superior, é bem a evidência de que esta antologia poderia ser lida como uma antecipação da política do XXI Governo, liderado por António Costa, para a ciência e o ensino superior. Uma antecipação expressa, por exemplo, na coincidência genérica entre a agenda política enunciada nas páginas 1083 e 1084 e a súmula da carta de princípios de orientação para a Fundação para a Ciência e a Tecnologia ${ }^{2}$, assinada a 10 de fevereiro de 2016 precisamente por Manuel Heitor e Maria Fernanda Rollo (respetivamente Ministro e Secretária de Estado da Ciência, Tecnologia e Ensino Superior).

\section{REFERÊNCIAS BIBLIOGRÁFICAS}

Fiolhais, C. (2011). A ciência em Portugal. Lisboa: Fundação Francisco Manuel dos Santos.

Gago, J. M. (2008). Manifesto para a ciência em Portugal. Lisboa: Gradiva.

Martins, M. L. (2015). A liberdade académica e os seus inimigos. Comunicação Q Sociedade, 27, 405-420.

Pinto-Coelho, Z. \& Carvalho, A. (Eds.) (2013). Academics responding to discourses of crisis in higher education and research. Braga: CECS.

Rodrigues, M. L. \& Heitor, M. (Eds.) (2015). 40 anos de políticas de ciência e de ensino superior. Coimbra: Almedina.

\section{NOTA BIOGRÁFICA}

Madalena Oliveira é Professora Auxiliar do Instituto de Ciências Sociais da Universidade do Minho e membro do Centro de Estudos de Comunicação e Sociedade. Ensina Semiótica, História da Comunicação, Comunicação e Linguagens e Jornalismo e Som. É coordenadora do Grupo de Trabalho de Rádio e Meios Sonoros da Sopcom - Associação Portuguesa de Ciências da Comunicação, de que é também vice-presidente. É chair da secção de Estudos de Rádio da ECREA e diretora da revista Radio, Sound Q Society, lançada por este grupo em 2016. Integra o Fórum Ibero-americano de Pós-Graduação, uma comissão de assessoramento da Confibercom - Confederação Ibero-americana das

\footnotetext{
${ }^{2}$ Retirado de http://www.portugal.gov.pt/media/18501895/20160210-mctes-principios-fct.pdf.
} 
Associações Científicas e Académicas de Comunicação e coordena com Helena Sousa o Observatório de Políticas Públicas para a Comunicação do Centro de Estudos de Comunicação e Sociedade.

E-mail: madalena.oliveira@ics.uminho.pt

Instituto de Ciências Sociais, 4710-057-Braga, Portugal.

* Submetido: 14-10-2015

* Aceite: 23-10-2015 